\title{
A MODEL TO EVALUATE SUPPLY CHAIN TECHNOLOGY IMPLEMENTATION INFLUENCE ON ORGANIZATIONAL PERFORMANCE
}

\author{
Zeynab SOLTANY1, Reza ROSTAMZADEH ${ }^{2}$, Viktor SKRICKIJ $^{3}$ \\ ${ }^{1}$ Young Researchers and Elite Club, Tabriz Branch, Islamic Azad University, Tabriz, Iran \\ ${ }^{2}$ Dept of Management, Urmia Branch, Islamic Azad University, Urmia, Iran \\ ${ }^{3}$ Transport and Logistics Competence Centre, Vilnius Gediminas Technical University, Lithuania
}

Received 2 March 2018; revised 6 July 2018; accepted 8 July 2018

\begin{abstract}
Supply Chain Management (SCM) aims to achieve organizational competitiveness. By including SCM paradigm and Information Technology (IT), companies aim to enhance their responsiveness and flexibility, and by changing their operations' strategy, they attempt to improve their competitiveness. This study focuses on the organizational variable, IT capabilities, technological structure, and possible antecedents and their impact on Supply Chain Technology (SCT) implementation. This paper proposes a model to examine the way, which SCT implementation affects IT enabled Organizational Performance (OP). The data were achieved through the questionnaires, and then they were analysed by using Smart PLS 3 program. The data collected from 118 employees in IT sector of Iran's customs administration provide strong support to the proposed research model. The results of this research showed that SCT implementation has a mediating effect on IT enabled OP improvement. Besides, the study revealed that IT capabilities have the most and organizational variable has the least influence on implementation of SCT. Based on other organization's situations, they can use the suggested model with a little changes.
\end{abstract}

Keywords: supply chain technology, organizational performance, IT enabled, structural equation model, simultaneous factor analysis.

\section{Introduction}

Regarding different decision problems in Supply Chains (SCs) and other structures included in goods movements are highly complex and require many aspects such as technology, economics, organization, quality, safety, supplies reliability, interaction with environment and social issues that should be considered (Jacyna-Gołda et al. 2017). Suppliers, partners, and customers by using Supply Chain Management (SCM) plan can manage and implement the flow of products, service, and information in a way that business operations improve in terms of customer response, real-time control, agility, or speed (Zhang, Dhaliwal 2009). In other words, the combination of these considerations results in SCM. The integration of the key business processes ranging from end user to suppliers and other stakeholders functions is defined as SCM. The result of competition in current international marketplaces leads to companies that try to find effective strategies, which benefit them more than their competitors. In reality, competition is between the SCs, not among the com- panies (Rostamzadeh et al. 2015). Recently, companies in different businesses and Information Technology (IT) applications have extended different models and SC strategies. The goal is to achieve an effective responsiveness to customer demand, growing product variety, and speeding up the product obsolescence. IT has been developed very fast and information has grown on the internet. The result has completely changed communication and information inside and outside the industries (Persona et al. 2007).

The adoption of IT along an SC is a necessity to improve SC performance (Lai et al. 2006). All these facts show that IT is important in integrating suppliers/partnering firms in virtual enterprise and SC (Gunasekaran, Ngai 2004). IT usage in managing the process of SC is highly attended. It is shown that IT impact on firm performance is unclear. So, it does not guarantee the SC performance. Firms easily duplicate a particular adoptive technology; thus, IT often does not provide a competitive advantage for the adopting firms. Not surprisingly, determining

${ }^{*}$ Corresponding author. E-mails: r.rostamzadeh@iaurmia.ac.ir, rostamzadeh59@gmail.com 
how IT as a resource can create a sustained competitive advantage for a firm remains to be an unresolved issue (Wu et al. 2006). Continuous improvement in IT has completely changed many present businesses, and it has resulted in more efficient SCM. As sharing information increases between different companies in SCs, operational performance increases, customer service improves, costs are reduced, quality improves, and competition increases. Simchi-Levi et al. (1999) emphasize that by improved information sharing, variation reduces, reliable forecasts are achievable, responses become quicker and supply becomes more adjustable. Fiala (2005) says that it makes the cooperation easier. Moreover, it reduces bullwhip effect and increases shared benefits. As many have explained (Breu et al. 2002), information systems act as a crucial part in development of intelligence. Flexibility and Speed cannot be gained without information systems. Therefore, many companies, to improve their SC operations, have invested in integrated information systems such as Customer Relationship Management (CRM) and Enterprise Resource Planning (ERP) (White et al. 2005).

The purpose of this study is to make sure how organizational variable, IT capabilities, technological structure, and possible antecedents might impact the SCT implementation. In this paper, we try to understand SCT success impact on Organizational Performance (OP). Understanding the determinants and outcomes of using SCT helps the companies to know how to make improvements. In short, this paper aims on providing a framework to clarify effective factors, by which the impact of SCT can be evaluated:

- in order to determine the effective factors for successful SCT implementation and the OP, a model and a framework are provided;

- evaluation of the impact of organizational variable, IT capabilities, technological structure, and possible antecedents on the SCT implementation success;

- evaluating the effect of successful SCT implementation on IT enabled OP.

The remainder of this paper is as follow. Section 1 provides the background of literature review. Section 2 presents the hypotheses and theoretical bases of the research model. Section 3 outlines the research methodology and measures. Section 4 discusses results and managerial implication. Finally, directions and conclusion for future study are presented.

\section{Review of literature}

In this section, the theoretical framework of organizational variable, IT capabilities, technological structure, IT and SCT implementation, OP are discussed and then the relationship between SCT implementation, and OP are explained.

Russell and Hoag (2004) proposed an approach to find out the way organizational influences are designed to improve business performance. By a theoretical framework, they understand and analyse the implementation of IT.
This framework is called diffusion approach. The outcome of this approach is that organizational factors such as user's perception, the firm's culture and various leadership factors influence the success of implementations. IT is crucial in collaboration between SC partners and it affects inside organization partnerships. In this regard, four aspects of supplier-retailer relationship are selected. It involved direct interviews and observation with five pairs of retailers and suppliers. The outcome was that existing relationship between partners constrains and enables the IT influence on inter organizational collaboration, and IT strengthens and stabilizes the existing collaboration. So, overall relationship must move based on IT-based inter organizational effort. Lin and Tseng (2006) developed a conceptual Structural Equation Model (SEM) to show the indirect and direct influence of Manufacturing Participation Strategy (MPS), Information Technology Application (ITA), and Supply Chain Participation Strategy (SCPS) on OP and Customer Satisfaction (CS) from a strategic view. This paper points out a critical pivotal variable and provides a useful conceptual SEM for managers to enhance the competitive advantage and implement SCM more effectively. The result is that in order to achieve OP, planning MPS plays a vital role. It shows that in an SC system, integrating operations with partners is strategically important. It shows that MPS requires the linkage of external market needs with internal consideration. Being engaged in business strategy planning requires the extending of CS and $\mathrm{OP}$ of a firm. This is an approach used for planning the SC system. IT deeply influences the performance of an SC. Also, the key personnel who takes part, enhances the quality of policy making in SCM functions. So, firm's being capable of applying appropriate IT, and appropriate personnel's taking part in policy-making are two important factors for success in implementation of the SC systems. Dedrick et al. (2008) investigated the relationship between the number of suppliers a manufacturer employs and his/her use of its e-procurement. They found that, at the aggregate level, there is no relation between number of suppliers and e-procurement in the manufacturing industry. However, rather than standard goods, e-procurement for custom goods is more associated and it involves more asset specific relationships. The degree of supplier - buyer consolidation affects the positive association between number of suppliers and e-procurement and it indicates that deeper consolidation of buyer-supplier information systems can help buyers to achieve their customized requirements in a better situation. Boon-itt (2009) found out the role of IT and SC combination on the performance of production cost. The goal was to expand the understanding of integrating SC by means of IT selection. The results show that cooperation/decision has important effect, which helps IT to make the supplier and customer relation more successful. The outcomes from his study create a framework, which link SC integration strategies and cost of production. This linkage leads to a useful understanding to how configure information technologies to expand 
production cost performance. To examine a positive indirect relationship by information sharing and information quality, and a positive relationship between the firm's performance as understood by retailers and determined use of ITs used for management.

Ngai et al. (2011) analysed the effect of relationship between capability and SC ability on performance of firm. The influence of CS ability on firm performance has been accepted, but from the inter-organizational partnership point of view, they study more about the interaction. According to the view related to resource and by applying a multi case study method in this study, they create a conceptual model. Their findings show that clarifying the difference between SC ability and SC capability, and their influence on firm performance is important. Their research adds to the understanding of the complexity of SC capability and expands the conceptual and real literature on SC ability. Prajogo and Olhager (2012) integrated material and information flows between SC partners and their influence on operational performance. Particularly, they have examined the role of long-term relationship of supplier as the integration's driver. They find that operations' performance is significantly influenced by integration of logistics. Information technology capabilities and information sharing both have high effects on integration of logistics. In addition, supplier's long-term relationships have high indirect and direct effects on performance; the indirect effect is from the effect on logistics integration and information integration. Jin and Kang (2013) studied outcomes and antecedents of global sourcing and IT in the SC of US apparel. They suggested a model, which integrates three firm predecessors (firm size, top management commitment to global sourcing, and firms' global intelligence) and results of IT operation and global sourcing (financial, strategic, and operational performance). Their study showed that if the firm's global intelligence is greater, then the firm's size will be greater and consequently global sourcing participation will be higher. In turn, if the top management attentiveness to global sourcing is high and if size of the firm is grate, then the IT will be used very much. As the three levels of firm performance is increased by global sourcing participation, IT usage will cause a higher operational performance. Ye and Wang (2013) explored impacts resulted from assigning IT and sharing information on SC operational performance. Related to the view, which is based on resource, their study discovers IT assignment and information sharing as certain resources/ capabilities for CS collaboration. The outcome of this study was that operational performance is directly affected by both IT assignment and information sharing. Operational performance is indirectly affected by IT assignment through information sharing. In operational performance enhancement, IT assignment and information sharing have various stresses. In the emerging economy, the paradigm of resource capability-performance is continued to context of SC. Acar and Uzunlar (2014) probed the effects of developing process and IT on time-based SC perfor- mance. Then, the research's goal is to show the IT and process enhancement activities' single and multiple effects, which are based on time SC performance that is a major strategic element of the business competitiveness. The present study outcomes reveal that the importance of information sharing by IT is most of the times considered by firms, but using applications of intranet in this regard is at the second place. The surprise is that the time-based SC performance is not directly influenced by intranet subdimensions and internet. Also, they have no important interactive relationship. By this research one can understand that firms still don't operate in an SC, which is integrated by IT applications or don't consider the value to operate in an SC like that.

One of the findings of present study is the direct relationship between time-related SC performance and Process Development (PD) efforts. In addition, this relationship is reachable for all aspects of PD effort factor. The findings are important for PD efforts, which help to effectively manage material flows across an SC. This is also seen in time-based SC performance. Existing interactive relationships between IT application and PD efforts, when is considered with the IT systems' advantage in the integration of external and internal processes, as we expected supports these two factors' expected positive effects on time-based SC performance collaboratively. After we perform analysis of moderator effect (planning \& systems and computer \& engineering) of IT application and PD factors, our findings resulted from research support these expectations. Colin et al. (2015) explored communication and information technologies as key strategies for effective SCM in producing SMEs. This study aimed to analyse the relationship between SCM strategies, and Information and Communications Technology (ICT). The outcomes from this study indicate that the performance of the SCM is highly affected by strategies and ICT. By ICT, it is possible to manage the information resources (materials), and stay away from delays. This causes cost reduction and the client compliance increase; therefore, it encourages the organization's total competitiveness. Oh et al. (2016) proposed a research model to investigate the interaction effects of ICT and SC capabilities on firm performance. The results indicated significant moderating effects of ICT characteristics on the relationship between SC capabilities and firms' market performance, but observed are only weak moderating effects on the relationship between SCn capabilities and firms' financial performance. Singhry et al. (2016) examined the mediating effect of concurrent engineering of product design on the relationship between advanced manufacturing technology and SC performance. They study showed a positive relationship between all the variables. They also concluded that concurrent engineering of product design is a full mediator between advanced manufacturing technology and SC performance. Vanpoucke et al. (2017) investigated leveraging the impact of Supply Chain Integration (SCI) through information technology. They researches showed that operational inte- 
gration is indispensable to capture the benefits of information exchange. In addition, it pointed out that the impact of the use of IT is stronger for upstream integration. Kim (2017) analysed the correlation among integrative IT, SCI, and firm performance. They results showed that integrative IT is positively associated with firm performance through SCI. However, the integrative IT does not has a positive correlation directly with firm performance. It is considered that in the relationship between integrative IT and firm performance, a new approach such as business process-oriented view arguing that performance is yielded through the primary influence of IT is necessary rather than a traditional view that sets up their direct correlations. Wu and Chiu (2018) investigated SC collaboration with determinants and performance impact: Social capital, justice, and technology use perspectives. The findings showed that SC collaboration plays an important mediating role in reaching focal firm's performance. Also, an understanding of the SC collaboration facilitators is the major concern for practitioners. The empirical results have verified the theoretical contribution for demonstrating a high level of explanatory power of SC collaboration and focal firm performance. In particular, this study also indicates that IT support with SCTs before the capability of SC collaboration could be well improved, may need to first nurture a climate of user satisfaction on using the technologies for all partners.

\section{Research model and hypothesis}

Determining the effective factors, which improve the suggested research model is covered in this part. This is done by giving a new model. Figure 1 presents the proposed research model. We have discussed and illustrated twelve variables with aspects. To test the relationship between the framework's components, five theories are given in this section. Detailed theories and supporting features are explained in the next section. In the remainder of this section, the most important state of the art researchers are reviewed. The goal of this review is to know the effective factors, which improve the organizational performance. Twelve dimensions within for latent variables (organizational variable, technological structure, IT capabilities and possible antecedents) based on the past studies are discussed. We will first look at hypothesis $H 1$ in Figure 1 that positively links organizational variable to SCT implementation.

\subsection{Organizational variable}

This research focuses on three aspects of the organizational factors, i.e. organizational size, organizational culture and organizational climate.

Organizational size. Organization size (as defined by the number of employees) has received substantial attention from management writers and researchers as a fundamental component, which affects organizational shape, structure, and design (Connell 2001). Organization size can be defined in two ways - by revenues or by number of employees. In many studies, number of employees is used as a measure of company size, while annual revenues are used in other studies (Mabert et al. 2003).

Organizational culture. Organizational culture's concept was adapted for studies of organization management. Different scholars have different definitions of culture of organization and culture is almost every scholar's attitude of mind (Bali et al. 1999). Gross and Rayner (1985) suggested that the organization culture was beginning result of the continuing discussions about assets, meanings, and values between an organization's members. Re-

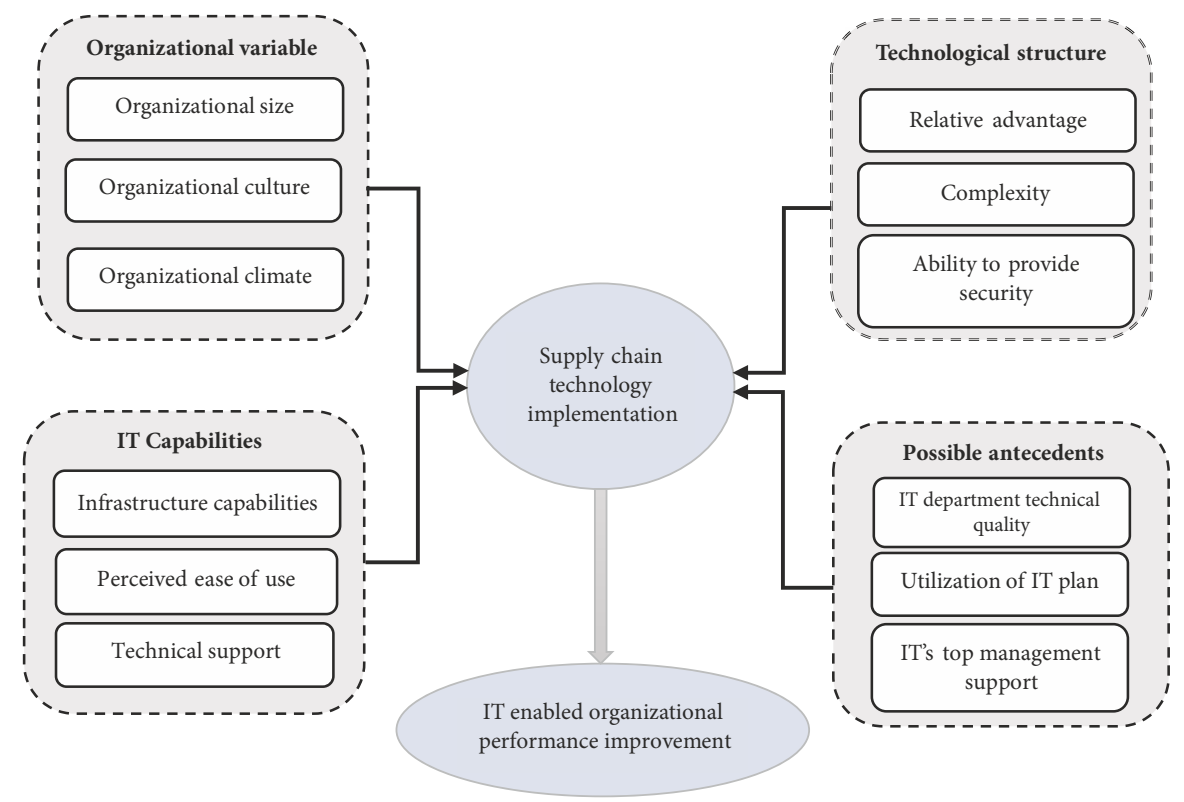

Figure 1. Model of research 
cently, organization culture was very important in SCM field (Goffnett et al. 2012), this is because the relationship between customers and suppliers is influenced by organizational culture. The evidence shows that organization culture literature is primarily concerned by values, predictability, ideas, points of view and theories. Interactions across relevant employees, end customers, suppliers and competitors are also identified by organizational culture. Chang and Lin (2007) suggest that the organization' actions are taken toward the organizational culture goals. Schein (1990) took an organization's norms, climate, and attitudes as organizational culture. Local processes build these characteristics and they can be changeable or stable. Hatch sees organizational culture as a complex set of symbols, artifacts, assumptions, beliefs, and values, which a firm, in its business implementation, should take them into account. Firms with strong organizational culture seem to have the capacity to justify with the market needs and have management systems, which are highly improved. If a firm wants to do better than the other, it has to take a defensible and proactive position toward its organizational culture. Organizational culture has much feel on SCM and SC ability, which allows it to serve as a significant determinant of competitive advantage (Malekifar et al. 2014).

Organizational climate. The organizational members who are working in that organization, affect personal motivation and action, and at the same time represent a multi-dimensional measure of the work situation, which is referred as organizational climate (Chen et al. 2012). In particular, organizational climate refers to an environment, which is linked with the beliefs, senses, and actions of every employee (Bock et al. 2005), and it has achieved much attention in previous studies. In a point of view, organizational climate is the organization's internal environment quality, which is relatively continuous, and members of the organization experience it and they are influenced by it. It can be explained as a value of a specific set of attributes or features of the environment (Ramayah et al. 2013). In understanding organizational members' characteristics, organizational climate plays an important role (Schulte et al. 2009).

Following theories are taken from previous studies, present arguments and evidence: H1: the organizational variable will effectively influence the supply chain technology performance.

\subsection{IT capabilities}

In order to change management in a firm, and manage knowledge efficiently and effectively, one needs IT capabilities (Wu et al. 2006). The previous studies show IT capabilities impact on a performance of a firm. On the other hand, there are unwrapped mechanisms that by using them, IT improve its performance, but the role and statement of the mechanisms remain unclear (Yan, Sengupta 2011). In fact, especially in the context of SC, scholars have to study more about the IT capabilities, which have influential mechanisms (Liu et al. 2013).
Flexible IT infrastructure. A firm's ability in establishing a complete set of technological resources is referred as flexible IT infrastructure. These resources provide the bases of IT applications development (Saraf et al. 2007). Particularly, an IT infrastructure, which is flexible is specified by following facts: (1) IT components' connection or connectivity, and other components, which are with partners of the channel or in the firm; (2) the ability or harmony in sharing any kind of information such as text, image, video, audio, data, and among others, across any IT component with partners of the channel or within the firm; (3) the ability or modularity, by without grate effort, easily add, change and remove any component of the infrastructure (Chung et al. 2003). By a flexible IT infrastructure and by expanding knowledge reach and richness, one can improve engaging capacity (Zhu et al. 2006). The firm by help of this capability can update, standardize and connect elements of IT, and as a result, one can easily integrate the data sources across and within the boundaries of the organization. IT components' connectivity allows the firm to keep in touch and exchange knowledge with channel partners, and as a result, the firm's knowledge expands (Liu et al. 2013).

Perceived ease of use. The Technology Acceptance Model (TAM) was suggested by Davis (1989). This model evaluates the users' accepting degree of a new system. TAM focuses on two important acceptance facts: one is perceived usefulness and the other id perceived ease-ofuse. The former refers to a person who thinks that a specific system would help him or her to improve his or her way of doing the job, and the latter refers to users, which think that technology by itself will be adapted and there is no need for human effort (Navimipour, Soltani 2016).

Technical support. Number of services that enterprises by using them help users of technology or goods is referred as technical support. For example when a user and a master interact with each other, the amount of the work and behaviour of the user and the master, providing and receiving feedback, and interacting with course materials may be affected by the used technology (Rubin et al. 2013). In order to implement IT in SCM, one needs a project management approach for the planning and implementation of IT projects. In this regard providing moral, financial, technical, and top management support is necessarily required (Gunasekaran, Ngai 2004).

Following hypothesis is taken from previous studies' arguments and evidence: H2: the supply chain technology implementation is highly influenced by capabilities of SC.

\subsection{Technological structure}

Relative Advantage. If a new system is economical, more effective or more efficient, then it has advantage over the old systems. Because the new system is consistent with the organizations past needs and experiences, and existing values, then it is seen as a compatible system. For instance, if a firm's culture emphasizes reliability more than competitiveness, then the new system's reliability would 
be more successful than price related innovations. If understanding the new system usage is difficult, it is related to its complexity degree (Rogers 2003), it is not related to adoption. In companies, which IT is adopted, complexity plays a role (Russell, Hoag 2004).

Complexity. Complexity is not related to adoption. In companies, which IT is adopted, complexity plays a role. Complexity should be low in a new system. Complexity of Allied Signal was low. The frustrated director of product line understood the ways the system functions. Although it was "a great tool", the director didn't show that he was overwhelmed with complexity. The tool of technology and the processes, which were enabled at allied signal were understood by people, but they have not yet understood the innovation's relative advantage over the old system (Russell, Hoag 2004).

Ability to provide security. Security is defined as a threat, which creates "circumstance, condition, or event with the potential to cause economic hardship to data or network resources in the form of destruction, disclosure, modification of data, denial of service and/or fraud, waste, and abuse (Nasri, Charfeddine 2012).

The following hypothesis is taken from previous studies and discussions: H3: the technological structure will positively influence on supply chain technology implementation.

\subsection{Possible antecedents}

Supply Chain Technologies (SCT) is a subset of traditional IT. The activities of a firm is facilitated by the SCT (Saldanha et al. 2015). Communication across the organizational boundaries and information sharing are empowered by SCT (Saeed et al. 2010). SCM is needed to understand the use of SCT or its antecedents. If managers achieve this understanding, they can easily use SCT within SC networks, and they can improve operational efficiency. In addition, the performance outcomes from using CT is very important for operators (Bala, Venkatesh 2016), especially for SC managers, because the firms pay money and work for SCT implementation within their SCs (Mishra et al. 2013).

Technical quality of IT department. The services and technical value of the products, by which the department compared to the firm's nearest competitors IT departments are supplied, is defined as the IT department technical quality. Software maintenance efficiency, operating systems' performance and hardware, end user support, business applications' software performance, communications services' efficiency, IT expenditures and investments are included in value measures. The value of IT department can directly affect the management of that entity; thus, determining IT department's value is very important in current environment, and it can lead to outsourcing, reorganization, and restructuring the department of IT. Department's impact on the SC should be huge, because it is important in the start, implementation, and development of IT resources (Byrd, Davidson 2003).
IT plan utilization. IT plans' importance to the IT resources' successful applications have been highlighted by past scholars (Boynton, Zmud 1987). Among successful use and plans of IT there is a positive relationship. Premkumar and King (1994) analysed the IT planning linkage, its participation in the organization's performance, and as a result, they found a positive relationship. Finally, Doll (1985) announced that firms, which have successful systems, three times more than other firms have formal plans and use the plans to improve their systems. IT applications have influence across many activities. Functions of the organizations with functions of other organizations are integrated by some of these activities and some integrate with external entities such as customers and suppliers. Utilizing IT plans can enhance the communication between business and IT managerial. By including the IT resources in the firm, the effectiveness of IT resources in the organization can also be increased (Reich, Benbasat 2000). IT applications in the SC may be operated and developed by enterprise-extensive managers with line managers (Byrd, Davidson 2003).

IT's top management support. IT's top management support refers to the top managers and SC partners who understand the benefits from sharing information and supporting its quality. For a number of researchers (Balsmeier, Voisin 1996), the most important driver of any successful change in the organization is top management support IT. If top management support wants to better understand their top managements their potential partners, they must understand and use partners who are important in operations and influence the market ( $\mathrm{Li}, \mathrm{Lin}$ 2006). An organization's ability in this regard is changeable. Top management support influences the ability of an organization in this area. It plays an important role in making value in the SCM. Without its help and observation, firm's IT systems would not be very successful. Top management support in several areas of IT value study and implementation of IT has been examined, and it has been a key to success for a long time (Ngai et al. 2011). Both engagement and participation should be included in Top management support. In some ways, it shows the importance of what top management executive places on IT (Byrd, Davidson 2003).

So the following hypothesis proposed: H4: the possible antecedents will positively influence the supply chain technology implementation.

\subsection{Supply chain technology implementation and IT enabled organizational performance improvement}

Supply chain managers and leaders need to understand, which technology trends will be the dominant forces of change and continuous improvement in the coming year. In order to cause an integrated SCM inside or across the organizational boundaries, we should implement tools or techniques, which are referred as SCT (Autry et al. 2010). Many have emphasized SCT adoption (Liu et al. 2010), but its utilization has taken little notice. If firms only 
adopt SCT, they would not make much benefit. Rather, they should be actually used in business processes to create value and capabilities. In this paper, SCT is used on a way that it creates capabilities and value for firms (Liu et al. 2016). The information technology used to facilitate information quality and information sharing in SCM is defined as IT enablers. Information technology's developments have fuelled the movement toward business process and SC integration. Organizations cannot effectively be leaders in SCM, provide superior customer service, and manage cost without leading-edge information systems. The measurement of organization performance can be done by different aspects. No single business affects all the aspects on the same way (Walker, Ruekert 1987). Madu et al. (1996) studied the organization performance and quality management relationship. The results as performance measures were productivity, cost, profitability, competitiveness, growth of sales, increase of profit and market shares. Biswas and Narahari (2004) said that measuring SC performance is divided in two categories. One is qualitative measures such as quality of product and SC, and the second one is measures of quality such as response time of SC, order-to delivery lead time, etc.). Because most firms don't want to reveal information to other firms, objective performance data are not available. On the other hand, about the objective measures of performance, organization scholars are generally in common. In addition, financial statements may not be right, because they are not commonly investigated (Lin, Tseng 2006). At the range of operational strategies, IT-enabled SCM is very important for firms, because they can manage both their external relationships, and their internal operation efficiency, particularly the cross-company workflow in an SC (Zhang, Dhaliwal 2009).

Following theory is taken from previous evidence and arguments: H5: the supply chain technology implementation will positively influence the IT enabled organizational performance improvement.

\section{Data analysis and research method}

For testing the research model factually, survey method was selected. The present study is a descriptive-correlation type for information gathering and applied in the nature.

\subsection{Construct measurement}

Tools were adapted, which were successfully tested in the past. These tools were changed to suit our particular needs, but not on a way to harm its main purposes. Then, survey instrument was created. Capabilities of IT were justified from scales by Liu et al. (2013). Technological structures were adapted from Russell and Hoag (2004). Possible antecedents of three dimensions are as: top management, IT plan utilization, and IT department technical quality. The measurement items were adapted from Byrd and Davidson (2003). Possible antecedents' all first order constructs had good validity of convergent $(>0.70)$. The three dimensions of organizational variable items: organi- zational size, organizational culture, organizational climate were adapted from Mamillo (2014). In their survey, the organizational variable's second order constructs had good validity of convergent $(>0.70)$.

\subsection{Sample characteristics and data source}

To check for the face validity of the instrument, pre-tests were done before starting the survey. The survey instrument initially was done with 9 volunteer respondents whom were fit for the respondent profile. To measure the elements of the model, a questionnaire was designed. Experts with significant experiences in the SC helped to revise the questionnaires. Standard and reliable resource were used to examine the validity of the questionnaire and after making the revising, it was distributed among the statistical sample. Through a large-scale web-based survey, by office automation system, data was collected. The questionnaire was pre-tested by three professionals and by two academics to check its content usability and reliability. Instead of some minor editing changes that were done for making the questionnaire complete and easier to understand, no other changes were found to be required. The employees of IT section of all customs in Iran were presented with the questionnaire. We used the SPSS 24 (https://www.ibm.com/analytics/spss-statistics-software) and SMART-PLS (https://www.smartpls.com) (partial least squares) software package. A five point Likert-type scale was used for all questionnaire items. Sample characteristics are shown in Table 1. Of the 118 respondents,

Table 1. Characteristics of respondents.

\begin{tabular}{|c|c|c|}
\hline & Frequency & Percentage \\
\hline \multicolumn{3}{|c|}{ Gender } \\
\hline Female & 47 & $40 \%$ \\
\hline Male & 71 & $60 \%$ \\
\hline Total & 118 & $100 \%$ \\
\hline \multicolumn{3}{|c|}{ Age } \\
\hline $20 \ldots 30$ & 15 & $13 \%$ \\
\hline $31 \ldots 40$ & 57 & $48 \%$ \\
\hline $41 \ldots 50$ & 45 & $38 \%$ \\
\hline$>50$ & 1 & $1 \%$ \\
\hline Total & 118 & $100 \%$ \\
\hline \multicolumn{3}{|c|}{ Education } \\
\hline Associate Degree & 5 & $4 \%$ \\
\hline Bachelor's degree & 98 & $83 \%$ \\
\hline Master's Degree & 15 & $13 \%$ \\
\hline Total & 118 & $100 \%$ \\
\hline \multicolumn{3}{|c|}{ Work Experience } \\
\hline$<5$ & 28 & $24 \%$ \\
\hline $6 \ldots 10$ & 21 & $18 \%$ \\
\hline $11 \ldots 15$ & 22 & $18 \%$ \\
\hline $16 \ldots 20$ & 46 & $39 \%$ \\
\hline $21 \ldots 25$ & 1 & $1 \%$ \\
\hline
\end{tabular}


the median age was between 31 and 40 . The data collection took place in July 2016. The target population included all employee of IT custom's administration in this research. Based on overall construct and these measures, 32 survey questions were identified to measure the influence of implementation of SCT. Toward IT enabled organizational performance improvement with purposive sampling method, 124 questionnaires were distributed totally that 121 of them were returned, and three of them were incomplete and discarded. The result was totally 118 produced usable questionnaires.

\subsection{Data analysis}

The study model was tested by using SEM techniques. SEM technique is an approach for testing theories. The theories are about relations between variables. They can be used for both theory testing and predictive applications. PLS is a technique based on regression and is originated from path analysis (Wold 1985). This approach provides the testing of the structural model and measurement. PLS approach is flexible in distributional assumptions, and it needs small size of samples. Also, it is strong in managing complex predictive models; therefore, it is superior to other SEM approaches (Chin, Newsted 1999). Simultaneous factor analysis with hypothesis testing were done by use of PLS. in some situations, small sample size is done well by PLS, but in other situation, it is better to be careful with small sample size; therefore, in order to minimize problems of deviation from normality, they suggest a ratio of 15 respondents for one parameter (Marcoulides, Saunders 2006). In this research, the 124 cases sample is very high than the required sample, which is $7.15=105$ responses to satisfy the above criteria. For many reasons, using PLS is encouraged. Because it can manage both reflective and formative constructs. So, PLS will not have problem about the difference between these two constructs (Chin 1998b). In our model, there is a high correlation between certain constructs. Comparing with traditional approaches such as Ordinary Least Squares (OLS) regressions, the potential multicollinearity is not really a matter in PLS. Finally, comparing PLS to OLS, the former does not have a restriction on the normal sampling distribution.

\subsection{Analysis methods and measurement model}

Before testing the hypotheses, by using two types of validities, we will first asses the measurement model: convergent and divergent validity (Chin 1998b). Two statistical techniques were used to analyse the research outcomes. Testing reliability and validity of the measurement items involves the use of first stage analysis. For testing convergent and divergent validity, we use the measurement (outer) model. By using internal construct reliability and consistency reliability, the reliability measures of the constructs were applied. We evaluated divergent validity by comparing the correlation to square root variance between latent constructs. The hypothesis and structural (inner) model's testing is at the second stage. Single pair-correlations as well as the $t$-value from the PLS modelling. As hypothesized, the strength of the relationships between two variables may be measured. By using Cronbach's, the internal validity of the measurement items were checked. The smallest value was 0.72 , which shows reliability's satisfactory level. We conduct confirmatory factor analysis to test the measurement model. It checks the instrument items' convergent and divergence validity. To the case of formative constructs, AVE and composite reliability are not related (Chin 1998b). Factor loadings showed loadings of more than 0.67 . If early stages of the research reliability coefficients between 0.5 and 0.6 are considered as enough, then minimum of 0.70 loading threshold is recommended (Nunnally 1967). Validity of convergence and divergence's scales were tested by use of confirmatory factor analysis. The constructs' internal consistency is evaluated by use of composite reliability (Fornell, Larcker 1981b). Nunnally (1967) recommended composite reliability level of 0.7. It can be used to evaluate internal consistency. The range, by which multiple items measure the same construct is indicated by convergent validity. When construct of AVE is at least 0.5 , it is enough. Table 2 presents measurement model's tests results. Composite reliability of each construct is from 0.84 to 0.94 . It is above the threshold 0.70 that Nunnally has recommended. In addition, The AVEs exceed from $50 \%$. It shows that scale shows a strong internal reliability.

Table 2. Scale reliabilities and convergent validity

\begin{tabular}{|l|c|c|c|}
\cline { 2 - 4 } \multicolumn{1}{c|}{} & AVE & CR & $\begin{array}{c}\text { Cronbach's } \\
\text { Alpha }\end{array}$ \\
\hline Organizational variable & 0.64 & 0.88 & 0.82 \\
\hline IT capabilities & 0.64 & 0.84 & 0.72 \\
\hline Technological structure & 0.66 & 0.88 & 0.83 \\
\hline Possible antecedents & 0.61 & 0.86 & 0.79 \\
\hline $\begin{array}{l}\text { Supply chain technology } \\
\text { implementation }\end{array}$ & 0.59 & 0.94 & 0.93 \\
\hline $\begin{array}{l}\text { IT enabled organizational } \\
\text { performance improvement }\end{array}$ & 0.58 & 0.89 & 0.72 \\
\hline
\end{tabular}

The divergent validity of scale was evaluated by use of benchmark. Fornell and Larcker (1981a) suggested the benchmark. From the factor, AVE's square root should be greater than the correlation, which is shared between the factor in the model and other factors (Chen et al. 2012). The inter-construct correlations, with the square roots of the AVE of each construct in the diagonal elements is shown in Table 3.

\subsection{Hypothesis testing}

Predicting the hypothesized relationships in the research model is the next step on the SEM (Figure 1). To estimate the path coefficients and other model parameters, in a way to minimize the amount of unexplained variance or maximize the explained variance, the PLS-SEM algorithm was used (Hair et al. 2017). The strength of relationship between two constructs is shown by the path coefficient. According to Chin (1998a) and Pi et al. (2013), having a 
Table 3. Discriminant assessment and correlation matrix

\begin{tabular}{|l|c|c|c|c|c|c|}
\cline { 2 - 6 } \multicolumn{1}{c|}{} & $\begin{array}{c}\text { Organizational } \\
\text { variable }\end{array}$ & $\begin{array}{c}\text { IT } \\
\text { capabilities }\end{array}$ & $\begin{array}{c}\text { Technological } \\
\text { structure }\end{array}$ & $\begin{array}{c}\text { Possible } \\
\text { antecedents }\end{array}$ & $\begin{array}{c}\text { Supply chain } \\
\text { technology } \\
\text { implementation }\end{array}$ & $\begin{array}{c}\text { IT enabled } \\
\text { organizational } \\
\text { performance } \\
\text { improvement }\end{array}$ \\
\hline Organizational variable & 0.80 & 0.72 & 0.80 & & & \\
\hline IT capabilities & 0.62 & 0.71 & 0.81 & 0.78 & & \\
\hline Technological structure & 0.63 & 0.70 & 0.75 & 0.74 & 0.77 & \\
\hline Possible antecedents & 0.72 & 0.73 & 0.72 & 0.72 & 0.62 & 0.76 \\
\hline $\begin{array}{l}\text { Supply chain technology } \\
\text { implementation }\end{array}$ & 0.60 & 0.71 & 0.76 & 0.72 & \\
\hline $\begin{array}{l}\text { IT enabled organizational } \\
\text { performance improvement }\end{array}$ & & & & & \\
\hline
\end{tabular}

minimum of 0.2 path coefficient is recommended, but 0.3 or more than that would make the case stronger. In order to specify the importance of the path coefficient, the bootstrapping approach was used in PLS. We use path coefficients $R^{2}$ and $t$-value to test our hypotheses and descriptive power of the model. In addition, the significance of coefficient can be reached in different levels with different $t$-values $(p<0.1$, when $t>1.64 ; p<0.05$, when $t>1.96$; $p<0.01$, when $t>2.56)$. $t$-value quantities are the standard range and strong for all variables. The results of the analysis is shown in Figure 2. Three hypotheses were significant at the 0.90 and 0.99 level $(p<0.1, p<0.01)$ and all the other hypotheses were supported. For the hypothesized relationships, Table 4 shows the estimates of the parameters and values of $t$. The relationships between unused variables or the constructs that were hypothesized in the research model are represented by the structural model.

Overall, the outcomes present enough evidence to support all the hypotheses $(H 1, H 2, H 3, H 4$ and $H 5)$. Figure 2 shows the structural model's results. As data in Table 4 show, the achieved results from the sample $t$-test and path coefficient show that variables in the model have a positive and high effect on IT enabled organizational performance improvement. Therefore, the structure of the model fits with the data.

\subsection{Structural model}

Index $R^{2}$. The percentage of a construct's variation, which is explained by the model is measured by $R^{2}$. In PLS, $R^{2}$ refers to 'the relative amount of variance of the dependent variable accounted or explained for by the explanatory variables jointly. It is the statistical measure of the variance's percentage in a dataset. For example if $R^{2}=0.831$, then $83.1 \%$ of the variance of the dependent variable is explained by the explanatory variables. Although 0 to 1 is the range of $R^{2}$, there is no a criterion. Generally, the higher the $R^{2}$, the higher the variance (Chen et al. 2012).

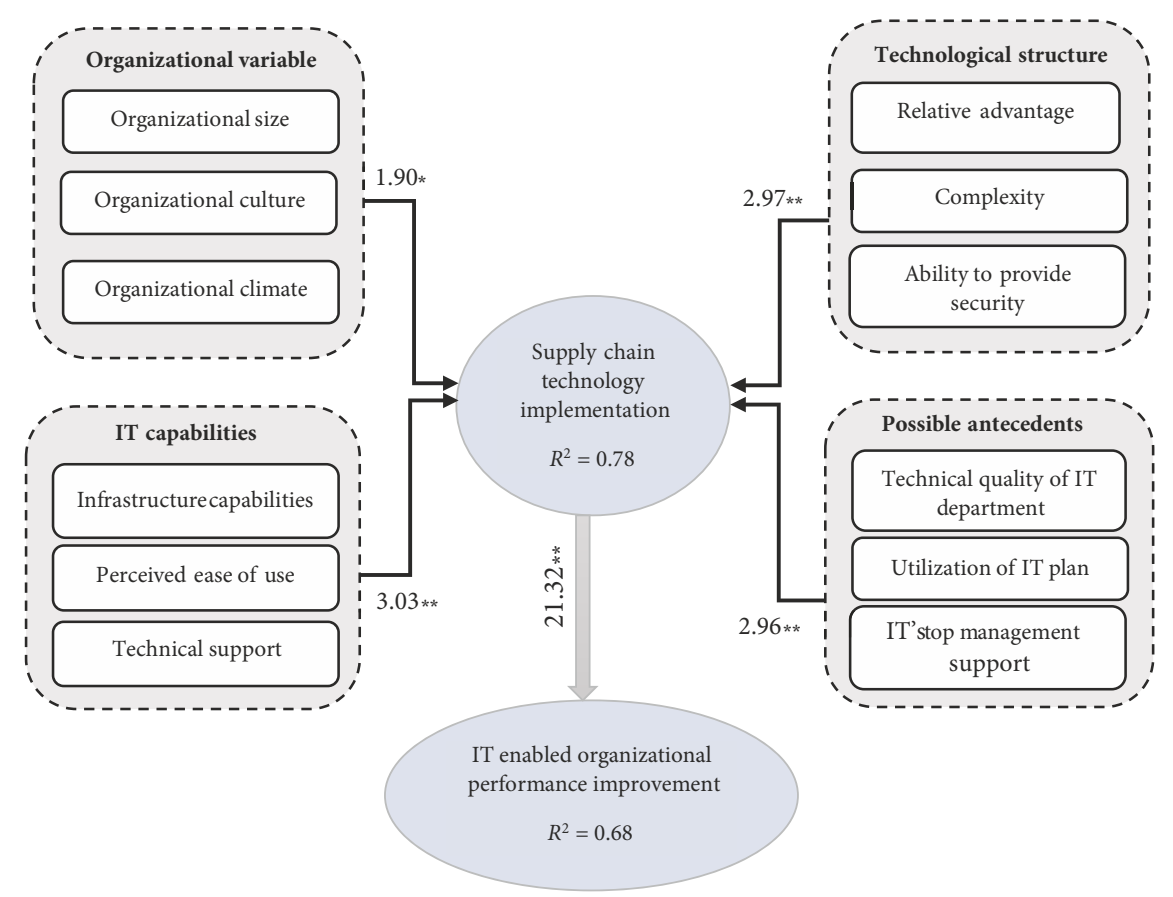

Figure 2. Research model based on PLS results (notes: ${ }^{\star}-p<0.1$; $^{\star *}-p<0.01$ ) 
Table 4. The hypothesis tests and results' summary

\begin{tabular}{|l|c|c|c|c|}
\hline \multicolumn{1}{|c|}{ Construct } & $t$-value & Path coefficient & Level of significance & Effect \\
\hline $\begin{array}{l}\text { Organizational variable } \rightarrow \text { Supply implementation of chain } \\
\text { technology }\end{array}$ & 1.90 & 0.18 & significant & significant \\
\hline $\begin{array}{l}\text { IT capabilities } \rightarrow \text { Supply chain implementation } \\
\text { of technology }\end{array}$ & 3.03 & 0.27 & significant \\
\hline $\begin{array}{l}\text { Technological structure } \rightarrow \text { Supply chain implementation } \\
\text { of technology }\end{array}$ & 2.97 & 0.29 & strong \\
\hline $\begin{array}{l}\text { Possible antecedents } \rightarrow \text { Supply chain implementation } \\
\text { of technology }\end{array}$ & 2.96 & 0.26 & strong \\
\hline $\begin{array}{l}\text { Supply chain technology implementation } \rightarrow \text { IT enabled } \\
\text { organizational performance improvement }\end{array}$ & 21.32 & 0.82 & stgnificant & strong \\
\hline
\end{tabular}

Therefore, we provided an integrated model to examine the impact of capabilities of IT, organizational variable, possible antecedents and technological structure on IT enabled organizational performance improvement and SCT implementation. Overall, the model explains $78.4 \%$ of the variance in SCT implementation, and $67.6 \%$ in IT enabled organizational performance improvement.

GOF index. Based on taking the square root of the product of the variance extracted with all constructs with the average $R^{2}$ value of the endogenous constructs and multiple indicators (Tenenhaus et al. 2005) regarding the overall quality of the research model, have developed an overall Good of Fitness (GOF) measure for PLS. GOF intends to account for the performance of PLS model at both the structural and measurement model with a focus on the overall prediction performance of the model (Chin 2010). The GOF index is obtained as the geometric mean of the average $R^{2}$ value and the average communality index (Chin 2010). Wetzels et al. (2009) define the effect size as large (0.36), medium (0.25), and small (0.1) GOF. The GOF index was calculated by formula:

$$
\mathrm{GOF}=\sqrt{\overline{\text { communality }} \cdot \bar{R}^{2}}=\sqrt{0.62 \cdot 0.71}=0.66 .
$$

A GOF value of 0.66 was obtained, which it passes the cut-off value of 0.36 for large effect sizes of $R^{2}$, and allows us to conclude that compared to the baseline values defined above, our model performs well.

\section{Discussion and managerial implications}

As shown in Table 4, the sample path coefficient and $t$ test's results show that organizational variable highly and positively affects the SCT implementation $(\beta=0.18, t=$ $1.90, p<0.1$ ), which supports H1. Also, IT capabilities have positive and high impact on SCT implementation ( $\beta=0.27, t=3.03, p<0.01)$. The complementarity between technological structure and SCT implementation $(\beta=0.29, t=2.96, p<0.01)$; thus, $H 3$ receives support. Accordingly, $H 1, H 2$, and $H 3$ were supported. Thus, the findings showed that organizational variable, IT capabilities and technological structure have significant effect on improving SCT implementation. $\mathrm{H} 4$ suggested a positive relationship between possible antecedents and SCT implementation, which supported $(\beta=0.26, t=21.32, p<0.01)$. The SCT implementation had a significant effect on IT enabled organizational performance improvement $(\beta=$ $0.82, t=22.62, p<0.01)$. The contributions of the paper are described below.

This section discusses the implications of the new findings of this study and summarizes them. From this study, we understand that electronic connections with the formation of IT artifacts, which links SC partners, can positively influence the relationship structure. By use of tools such as Inter-Organizational Information System (IOIS), ERP, and Groupware, IT bring the SC partners close together who are located in different areas. Although parties have formed formal structures, IT as a tool can improve performance and can enable the relationships. The following strategic guidelines are provided by these results: It can effectively and sincerely strengthen and build trust with suppliers. It increases integration of IT. This results in high performance. It shows the ways and limitations of the future studies.

The goal of this research is providing some key understandings about the operation and using SCT in the service factor. The primary results from this study show that organizational variables in many aspects played a significant role in SCT implementation. On the other hand, there has been little study about operation and using of large-size enterprise-wide systems. So, from this study we understand that size is a main factor for organizationalwide systems in the operation technique. This fact may affect service organization because it moves to implement the next wave of CRM systems and enterprise systems such as SCM. Norms, beliefs, values and expectations as culture's important factors, can build an organization's culture (Chang, Lin 2007). Organizational culture is an important factor, which influences SCM practices (Fawcett $e$ al. 2008). On the other hand, previous studies have ignored the synergistic effects of the various dimensions of organizational culture that co-exist within firms (Hartnell et al. 2011). We accept the organizational culture' important role in SCT implementation and formulation, but little studies have been done about the relationship between SCT implementation and organizational culture. In this 
research we examine the relationship among organizational culture and SCT implementation. In this paper we found that there is a direct link between SCT implementation and organizational culture. This paper suggests that a powerful organization's organizational culture influences the distributors and suppliers in the same SC.

IT infrastructure and IT capabilities both influence the firm's performance. SCT implementation can completely mediate this impact. In powerful organizations, organizational culture affects the supplier and distributors in the same SC. So in complex relations there must be precise examinations. Therefore, we understand that by adopting flexible IT infrastructure, a firm can enhance its absorptive capacity. The combination of a firm's lower order capabilities can be resulted in production of higher order capabilities. We concluded that IT capabilities do not directly influence the firm's performance but they can directly be affected by SCT implementation. The findings proved that SCT implementation is very important for a firm's performance. Also, this study expands our knowledge about the IT capability's impact on implementation of SCT. We see that absorptive capacity can form the implementation of SCT, but IT capability cannot directly influence the SCT. On the other hand, we see that easy SCT implementation had an indirect effect on organizational performance. It is clear that if using SC systems is difficult for consumers, then they would rate it as a useless system. So, SC systems should be designed on a way to be easily used and they should be useful in order to be succeeded. Capability of the system influences its usefulness. Also, in order to fulfil the users' expectations, the users' needs should be taken into account when designing an SC system. As the number of users increases, different knowledge domains should be included in the system. System capability also has a high impact on usefulness of SC systems. Because users' needs become divers, the domain knowledge should be adapted.

Many factors affect a company's performance improvement. Managers should plan IT strategies to improve performance. Planning managers should make sure that IT capabilities improve the management capabilities of both internal business processes and external SCM. All business processes and SC efficiencies are enabled by IT and should improve the performance of the firm. Nevertheless, it is necessary to evaluate the contributions of this study in light of certain limitations. This study talked about all dimensions of an SCT implementation, but it didn't discuss issues, which identify exact outcome relationships. In this regard, one remained question is the cost and benefit relationships. Other question is that later adopters achieve better returns or early ones? The former benefited from a better knowledge of implementation and upgraded systems, the latter benefited from competitive advantages. In answering such questions, this study is the first step. SCT systems should be studied more completely here. The optimal time to start an implementation of a large system should be considered. SCT systems are required to be studied more completely. May be there are other IT or organizational capabilities that can affect the performance of the firm. By focusing the effects of manufacturing, marketing and managerial capabilities on performance of the firm, future study may expand the area of this study. New types of contracts can be easily developed. So, the efficiency of decision allocating, contracting, and capacity investment can be increased. This study also has real suggestions for managers. For achieving better performance, especially in SCM, millions of dollars are invested in IT. If firms want to run competitive advantage and gain dynamic capabilities and higher operational, they should stick on their IT capabilities; otherwise, these investments do not gain the highest level of efficiency. Therefore, utilizing firms' IT capabilities is important because higherorder organizational capabilities are improved. This study provides necessary guidelines and knowledge.

\section{Conclusions}

The study introduced the impact of supply chain technology implementation in enhancing organization performance. It is used in Iran's customs organization. This study would help the organizations to get the best organization performance and find a way to use and practice the best information technologies.

Two important variables that aimed to measure supply chain technology implementation and IT enabled organizational performance improvement made this study to be important.

The study concluded that IT awareness is very important for organizations, which want to use it and gain the SCM advantages.

The study revealed that the IT capabilities have the most and organizational variable has the least impact on supply chain technology implementation. For saving employee's time and making use of working hours in a way, which is better for supply chain performance, the organizations also use IT.

In terms of research contributions, this study highlights the importance of supply chain technology and IT on organization performance.

Results provided types of IT that are effective in organization performance and managerial insights about specific integration practices.

In order to be able to focus on the right SCI, managers of IT strategy can, therefore, ask about types of IT implemented in their organizations.

Future work can use other variables of IT, which can influence SCM implementation of a firm. For example, IT alignment, IT advancement, internal IT integration, IT utilization, IT competence, IT flexibility and management commitment to IT.

The proposed model in this research could be used in other organizations considering their specific situations with slight modifications. 


\section{References}

Acar, A. Z.; Uzunlar, M. B. 2014. The effects of process development and information technology on time-based supply chain performance, Procedia - Social and Behavioral Sciences 150: 744-753. https://doi.org/10.1016/j.sbspro.2014.09.044

Autry, C. W.; Grawe, S. J.; Daugherty, P. J.; Richey, R. G. 2010. The effects of technological turbulence and breadth on supply chain technology acceptance and adoption, Journal of Operations Management 28(6): 522-536.

https://doi.org/10.1016/j.jom.2010.03.001

Bala, H.; Venkatesh, V. 2016. Adaptation to information technology: a holistic nomological network from implementation to job outcomes, Management Science 62(1): 156-179.

https://doi.org/10.1287/mnsc.2014.2111

Bali, R.; Cockerham, G.; Bloor, C. 1999. MISCO: a conceptual model for MIS implementation in SMEs, Information Research 4(4). Available from Internet: http://www.informationr. net/ir/4-4/paper61.html

Balsmeier, P. W.; Voisin, W. J. 1996. Supply chain management: a time-based strategy, Industrial Management 38(5): 24-27.

Biswas, S.; Narahari, Y. 2004. Object oriented modeling and decision support for supply chains, European Journal of Operational Research 153(3): 704-726.

https://doi.org/10.1016/S0377-2217(02)00806-8

Bock, G.-W.; Zmud, R. W.; Kim, Y.-G.; Lee, J.-N. 2005. Behavioral intention formation in knowledge sharing: examining the roles of extrinsic motivators, social-psychological forces, and organizational climate, MIS Quarterly 29(1): 87-111.

https://doi.org/10.2307/25148669

Boon-itt, S. 2009. The role of information technology and supply chain integration on production cost performance, in 2009 IEEE International Conference on Industrial Engineering and Engineering Management, 8-11 December 2009, Hong Kong, China, 1464-1468.

https://doi.org/10.1109/IEEM.2009.5373068

Boynton, A. C.; Zmud, R. W. 1987. Information technology planning in the 1990's: directions for practice and research, MIS Quarterly 11(1): 59-71. https://doi.org/10.2307/248826

Breu, K.; Hemingway, C. J.; Strathern, M.; Bridger, D. 2002. Workforce agility: the new employee strategy for the knowledge economy, Journal of Information Technology 17(1): 2131. https://doi.org/10.1080/02683960110132070

Byrd, T. A.; Davidson, N. W. 2003. Examining possible antecedents of IT impact on the supply chain and its effect on firm performance, Information \& Management 41(2): 243-255. https://doi.org/10.1016/S0378-7206(03)00051-X

Chang, S. E.; Lin, C.-S. 2007. Exploring organizational culture for information security management, Industrial Management \& Data Systems 107(3): 438-458.

https://doi.org/10.1108/02635570710734316

Chen, S.-S.; Chuang, Y.-W.; Chen, P.-Y. 2012. Behavioral intention formation in knowledge sharing: Examining the roles of KMS quality, KMS self-efficacy, and organizational climate, Knowledge-Based Systems 31: 106-118. https://doi.org/10.1016/j.knosys.2012.02.001

Chin, W. W. 2010. How to write up and report PLS analyses, in V. Esposito Vinzi, W. Chin, J. Henseler, H. Wang (Eds.). Handbook of Partial Least Squares, 655-690. https://doi.org/10.1007/978-3-540-32827-8_29

Chin, W. W. 1998a. Commentary: issues and opinion on structural equation modeling, MIS Quarterly 22(1): 7-16.

Chin, W. W. 1998b. The partial least squares approach to structural equation modeling, in G. A. Marcoulides (Ed.). Modern Methods for Business Research, 295-336.
Chin, W. W.; Newsted, P. R. 1999. Structural equation modeling analysis with small samples using partial least squares, in R. H. Hoyle (Eds.). Statistical Strategies for Small Sample Research, 307-341.

Chung, S. H.; Rainer, R. K.; Lewis, B. R. 2003. The impact of information technology infrastructure flexibility on strategic alignment and application implementations, Communications of the Association for Information Systems 11: 191-206.

Colin, M.; Galindo, R.; Hernández, O. 2015. Information and Communication Technology as a Key Strategy for Efficient Supply Chain Management in Manufacturing SMEs, Procedia Computer Science 55: 833-842.

https://doi.org/10.1016/j.procs.2015.07.152

Connell, J. 2001. Influence of firm size on organizational culture and employee morale, Journal of Management Research 1(4): 220-232.

Davis, F. D. 1989. Perceived usefulness, perceived ease of use, and user acceptance of information technology, MIS Quarterly 13(3): 319-340. https://doi.org/10.2307/249008

Dedrick, J.; Xu, S. X.; Zhu, K. 2008. Information technology and the number of suppliers in a supply chain: is there a relationship?, in Proceedings of the 41st Annual Hawaii International Conference on System Sciences (HICSS 2008), 7-10 January 2008, Waikoloa, HI, USA.

https://doi.org/10.1109/HICSS.2008.205

Doll, W. J. 1985. Avenues for top management involvement in successful MIS development, MIS Quarterly 9(1): 17-35. https://doi.org/10.2307/249271

Fawcett, S. E.; Magnan, G. M.; McCarter, M. W. 2008. Benefits, barriers, and bridges to effective supply chain management, Supply Chain Management: an International Journal 13(1): 35-48. https://doi.org/10.1108/13598540810850300

Fiala, P. 2005. Information sharing in supply chains, Omega: the International Journal of Management Science 33(5): 419-423. https://doi.org/10.1016/j.omega.2004.07.006

Fornell, C.; Larcker, D. F. 1981a. Evaluating structural equation models with unobservable variables and measurement error, Journal of Marketing Research 18(1): 39-50.

https://doi.org/10.2307/3151312

Fornell, C.; Larcker, D. F. 1981b. Structural equation models with unobservable variables and measurement error: algebra and statistics, Journal of Marketing Research 18(3): 382-388. https://doi.org/10.2307/3150980

Goffnett, S. P.; Cook, R. L.; Williams, Z.; Gibson, B. J. 2012. Understanding satisfaction with supply chain management careers: an exploratory study, The International Journal of Logistics Management 23(1): 135-158. https://doi.org/10.1108/09574091211226966

Gross, J. L.; Rayner, S. 1985. Measuring Culture: a Paradigm for the Analysis of Social Organization. Columbia University Press. 146 p.

Gunasekaran, A.; Ngai, E. W. T. 2004. Information systems in supply chain integration and management, European Journal of Operational Research 159(2): 269-295.

https://doi.org/10.1016/j.ejor.2003.08.016

Hair, J. F.; Hult, G. T. M.; Ringle, C.; Sarstedt, M. 2017. A Primer on Partial Least Squares Structural Equation Modeling (PLSSEM). SAGE Publications, Inc. 384 p.

Hartnell, C. A.; Ou, A. Y.; Kinicki, A. 2011. Organizational culture and organizational effectiveness: A meta-analytic investigation of the competing values framework's theoretical suppositions, Journal of Applied Psychology 96(4): 677-694. https://doi.org/10.1037/a0021987 
Jacyna-Gołda, I.; Izdebski, M.; Podviezko, A. 2017. Assessment of efficiency of assignment of vehicles to tasks in supply chains: a case study of a municipal company, Transport 32(3): 243-251. https://doi.org/10.3846/16484142.2016.1275040

Jin, B.; Kang, J. H. 2013. Antecedents and outcomes of global sourcing and information technology in the US apparel supply chain, The Journal of The Textile Institute 104(1): 57-66. https://doi.org/10.1080/00405000.2012.693275

Kim, H. J. 2017. Information technology and firm performance: the role of supply chain integration, Operations Management Research 10(1-2): 1-9.

https://doi.org/10.1007/s12063-016-0122-z

Lai, K.-H.; Wong, C. W. Y.; Cheng, T. C. E. 2006. Institutional isomorphism and the adoption of information technology for supply chain management, Computers in Industry 57(1): 93-98. https://doi.org/10.1016/j.compind.2005.05.002

Li, S.; Lin, B. 2006. Accessing information sharing and information quality in supply chain management, Decision Support Systems 42(3): 1641-1656.

https://doi.org/10.1016/j.dss.2006.02.011

Lin, C.; Tseng, H. 2006. Identifying the pivotal role of participation strategies and information technology application for supply chain excellence, Industrial Management \& Data Systems 106(5): 739-756. https://doi.org/10.1108/02635570610666476

Liu, H.; Ke, W.; Wei, K. K.; Gu, J.; Chen, H. 2010. The role of institutional pressures and organizational culture in the firm's intention to adopt internet-enabled supply chain management systems, Journal of Operations Management 28(5): 372-384. https://doi.org/10.1016/j.jom.2009.11.010

Liu, H.; Ke, W.; Wei, K. K.; Hua, Z. 2013. The impact of IT capabilities on firm performance: the mediating roles of absorptive capacity and supply chain agility, Decision Support Systems 54(3): 1452-1462. https://doi.org/10.1016/j.dss.2012.12.016

Liu, Z.; Prajogo, D.; Oke, A. 2016. Supply chain technologies: linking adoption, utilization, and performance, Journal of Supply Chain Management 52(4): 22-41.

https://doi.org/10.1111/jscm.12117

Mabert, V. A.; Soni, A.; Venkataramanan, M. A. 2003. The impact of organization size on enterprise resource planning (ERP) implementations in the US manufacturing sector, Omega: the International Journal of Management Science 31(3): 235-246. https://doi.org/10.1016/S0305-0483(03)00022-7

Madu, C. N.; Kuei, C.-H.; Jacob, R. A. 1996. An empirical assessment of the influence of quality dimensions on organizational performance, International Journal of Production Research 34(7): 1943-1962.

https://doi.org/10.1080/00207549608905006

Malekifar, S.; Taghizadeh, S. K.; Rahman, S. A.; Khan, S. U. R. 2014. Organizational culture, IT competence, and supply chain agility in small and medium-size enterprises, Global Business and Organizational Excellence 33(6): 69-75. https://doi.org/10.1002/joe.21574

Mamillo, D. 2014. The effect of organization culture and uncertainty in supply chain management - the Albanian beer industry, Theory, Methodology, Practice 10(2): 49-57.

Marcoulides, G. A.; Saunders, C. 2006. PLS: a silver bullet?, MIS Quarterly 30(2): 3-9. https://doi.org/10.2307/25148727

Mishra, S.; Modi, S. B.; Animesh, A. 2013. The relationship between information technology capability, inventory efficiency, and shareholder wealth: a firm-level empirical analysis, Journal of Operations Management 31(6): 298-312.

https://doi.org/10.1016/j.jom.2013.07.006

Nasri, W.; Charfeddine, L. 2012. Factors affecting the adoption of Internet banking in Tunisia: An integration theory of ac- ceptance model and theory of planned behavior, The Journal of High Technology Management Research 23(1): 1-14.

https://doi.org/10.1016/j.hitech.2012.03.001

Navimipour, N. J.; Soltani, Z. 2016. The impact of cost, technology acceptance and employees' satisfaction on the effectiveness of the electronic customer relationship management systems, Computers in Human Behavior 55: 1052-1066.

https://doi.org/10.1016/j.chb.2015.10.036

Ngai, E. W. T.; Chau, D. C. K.; Chan, T. L. A. 2011. Information technology, operational, and management competencies for supply chain agility: findings from case studies, The Journal of Strategic Information Systems 20(3): 232-249.

https://doi.org/10.1016/j.jsis.2010.11.002

Nunnally, J. C. 1967. Psychometric Theory. McGraw-Hill. 640 p.

Oh, S.; Ryu, Y. U.; Yang, H. 2016. Supply chain capabilities and information technology characteristics: interaction effects on firm performance, in 2016 49th Hawaii International Conference on System Sciences (HICSS), 5-8 January 2016, Koloa, HI, USA, 1417-1425. https://doi.org/10.1109/HICSS.2016.179

Persona, A.; Regattieri, A.; Pham, H.; Battini, D. 2007. Remote control and maintenance outsourcing networks and its applications in supply chain management, Journal of Operations Management 25(6): 1275-1291.

https://doi.org/10.1016/j.jom.2007.01.018

Pi, S.-M.; Chou, C.-H.; Liao, H.-L. 2013. A study of Facebook Groups members' knowledge sharing, Computers in Human Behavior 29(5): 1971-1979.

https://doi.org/10.1016/j.chb.2013.04.019

Prajogo, D.; Olhager, J. 2012. Supply chain integration and performance: the effects of long-term relationships, information technology and sharing, and logistics integration, International Journal of Production Economics 135(1): 514-522. https://doi.org/10.1016/j.ijpe.2011.09.001

Premkumar, G.; King, W. R. 1994. The evaluation of strategic information system planning, Information \& Management 26(6): 327-340. https://doi.org/10.1016/0378-7206(94)90030-2

Ramayah, T.; Yeap, J. A. L.; Ignatius, J. 2013. An empirical inquiry on knowledge sharing among academicians in higher learning institutions, Minerva 51(2): 131-154. https://doi.org/10.1007/s11024-013-9229-7

Reich, B. H.; Benbasat, I. 2000. Factors that influence the social dimension of alignment between business and information technology objectives, MIS Quarterly 24(1): 81-113. https://doi.org/10.2307/3250980

Rogers, E. M. 2003. Diffusion of Innovations. 5th edition. Free Press. 576 p.

Rostamzadeh, R.; Sabaghi, M.; Sofian, S.; Ismail, Z. 2015. Hybrid GA for material routing optimization in supply chain, Applied Soft Computing 26: 107-122.

https://doi.org/10.1016/j.asoc.2014.09.033

Rubin, B.; Fernandes, R.; Avgerinou, M. D. 2013. The effects of technology on the community of inquiry and satisfaction with online courses, The Internet and Higher Education 17: 48-57. https://doi.org/10.1016/j.iheduc.2012.09.006

Russell, D. M.; Hoag, A. M. 2004. People and information technology in the supply chain: social and organizational influences on adoption, International Journal of Physical Distribution \& Logistics Management 34(2): 102-122. https://doi.org/10.1108/09600030410526914

Saeed, K. A.; Abdinnour, S.; Lengnick-Hall, M. L.; Lengnick-Hall, C. A. 2010. Examining the impact of pre-implementation expectations on post-implementation use of enterprise systems: a longitudinal study, Decision Sciences 41(4): 659-688. https://doi.org/10.1111/j.1540-5915.2010.00285.x 
Saldanha, J. P.; Mello, J. E.; Knemeyer, A. M.; Vijayaraghavan, T. A. S. 2015. Implementing supply chain technologies in emerging markets: an institutional theory perspective, Journal of Supply Chain Management 51(1): 5-26. https://doi.org/10.1111/jscm.12065

Saraf, N.; Langdon, C. S.; Gosain, S. 2007. IS application capabilities and relational value in interfirm partnerships, Information Systems Research 18(3): 320-339. https://doi.org/10.1287/isre.1070.0133

Schein, E. H. 1990. Organizational culture, American Psychologist 45(2): 109-119. https://doi.org/10.1037/0003-066X.45.2.109

Schulte, M.; Ostroff, C.; Shmulyian, S.; Kinicki, A. 2009. Organizational climate configurations: relationships to collective attitudes, customer satisfaction, and financial performance, Journal of applied psychology 94(3): 618-634. https://doi.org/10.1037/a0014365

Simchi-Levi, D.; Kaminsky, P.; Simchi-Levi, E. 1999. Designing and Managing the Supply Chain: Concepts, Strategies, and Case Studies. McGraw-Hill.

Singhry, H. B.; Rahman, A. A.; Imm, N. S. 2016. Effect of advanced manufacturing technology, concurrent engineering of product design, and supply chain performance of manufacturing companies, The International Journal of Advanced Manufacturing Technology 86(1-4): 663-669. https://doi.org/10.1007/s00170-015-8219-3

Tenenhaus, M.; Vinzi, V. E.; Chatelin, Y.-M.; Lauro, C. 2005. PLS path modeling, Computational Statistics \& Data Analysis 48(1): 159-205. https://doi.org/10.1016/j.csda.2004.03.005

Vanpoucke, E.; Vereecke, A.; Muylle, S. 2017. Leveraging the impact of supply chain integration through information technology, International Journal of Operations \& Production Management 37(4): 510-530. https://doi.org/10.1108/IJOPM-07-2015-0441

Walker, O. C.; Ruekert, R. W. 1987. Marketing's role in the implementation of business strategies: a critical review and conceptual framework, The Journal of Marketing 51(3): 15-33. https://doi.org/10.2307/1251645

Wetzels, M.; Odekerken-Schröder, G.; Van Oppen, C. 2009. Using PLS path modeling for assessing hierarchical construct models: guidelines and empirical illustration, MIS Quarterly 33(1): 177-195. https://doi.org/10.2307/20650284

White, A.; Daniel, E. M.; Mohdzain, M. 2005. The role of emergent information technologies and systems in enabling supply chain agility, International Journal of Information Management 25(5): 396-410.

https://doi.org/10.1016/j.ijinfomgt.2005.06.009

Wold, H. 1985. Systems analysis by partial least squares, in P. Nijkamp, L. Leitner, N. Wrigley (Eds.). Measuring the Unmeasurable, 221-252.

Wu, F.; Yeniyurt, S.; Kim, D.; Cavusgil, S. T. 2006. The impact of information technology on supply chain capabilities and firm performance: a resource-based view, Industrial Marketing Management 35(4): 493-504.

https://doi.org/10.1016/j.indmarman.2005.05.003

Wu, I.-L.; Chiu, M.-L. 2018. Examining supply chain collaboration with determinants and performance impact: social capital, justice, and technology use perspectives, International Journal of Information Management 39: 5-19. https://doi.org/10.1016/j.ijinfomgt.2017.11.004

Yan, D.; Sengupta, J. 2011. Effects of construal level on the pricequality relationship, Journal of Consumer Research 38(2): 376389. https://doi.org/10.1086/659755
Ye, F.; Wang, Z. 2013. Effects of information technology alignment and information sharing on supply chain operational performance, Computers \& Industrial Engineering 65(3): 370377. https://doi.org/10.1016/j.cie.2013.03.012

Zhang, C.; Dhaliwal, J. 2009. An investigation of resource-based and institutional theoretic factors in technology adoption for operations and supply chain management, International Journal of Production Economics 120(1): 252-269.

https://doi.org/10.1016/j.ijpe.2008.07.023

Zhu, K.; Kraemer, K. L.; Gurbaxani, V.; Xu, S. X. 2006. Migration to open-standard interorganizational systems: network effects, switching costs, and path dependency, MIS Quarterly 30: 515-539. https://doi.org/10.2307/25148771 